\title{
Corpo lúteo persistente associado a infecções uterinas em rebanhos leiteiros da Zona da Mata-MG
}

\section{Persistent corpus luteum and uterine infections in dairy cows in the Zona da Mata region, Minas Gerais state}

\author{
Ademir de Moraes Ferreira, ${ }^{*}$ Wanderlei Ferreira de Sá, ${ }^{*}$ João Henrique Moreira Viana, \\ Carlos Antônio de Carvalho Fernandes, ${ }^{\star \star}$ Célio de Freitas ${ }^{\star}$
}

\begin{abstract}
Resumo
O exame ginecológico de 3408 fêmeas bovinas, em 50 rebanhos leiteiros da Zona da Mata de Minas Gerais, revelou 384 $(11,3 \%)$ casos de infecção uterina, das quais $186(5,5 \%)$ de primeiro grau ou catarral, $162(4,8 \%)$ do segundo grau ou mucopurulenta e $36(1,1 \%)$ do terceiro grau ou purulenta. Destas, 12 animais encontravam-se no período puerperal (até 90 dias pós-parto), com $10 \mathrm{em}$ anestro, dos quais três por corpo lúteo (CL) persistente. Nos 24 casos restantes os animais encontravam-se no período pós-puerperal (acima de 90 dias pós-parto), com 14 em anestro, dos quais seis por CL persistente, incluídos quatro fetos macerados. Não se verificou nenhum caso de infecção uterina do primeiro e segundo grau induzindo persistência de CL. Esta foi confirmada por palpação transretal (presença de CL no mesmo ovário e mesma posição em dois exames com intervalo de 10 a 12 dias), por dosagem de progesterona no sangue a cada sete dias, por observação visual do estro e pelo retorno do estro após aplicação de Prostaglandina $F_{2} a$. Os nove casos de infecção uterina do terceiro grau que provocaram anestro por persistência do CL correspondem a $0,3 \%$ do total de 3.408 vacas examinadas ou $25 \%$ dos 36 casos de infecção uterina do terceiro grau. Os resultados revelam baixa prevalência de CL persistente provocado por alteração do mecanismo luteolítico devido à infecção uterina, não representando importante causa de infertilidade nos rebanhos leiteiros estudados.
\end{abstract}

Palavras-chave: reprodução; metrite; corpo lúteo persistente; ovário; bovino.

\begin{abstract}
Rectal palpations performed in 3408 dairy cows belonging to herds of Zona da Mata, Minas Gerais State, Brazil, revealed 384 $(11.3 \%)$ cases of uterine infection, where $186(5.5 \%)$ were catarrhal, $162(4.8 \%)$ mucopurulent and $36(1.1 \%)$ purulent type. In these cases, 12 of the cows were founded in puerperal period (up to 90 days post-partum), 10 being in anestrus, three of them with persistent corpus luteum (CL). The remainder 24 cows were in the post-puerperal period (over 90 days post-partum), 14 being in anestrus, of which six presented persistent $C L$, where as four showing macerated fetus. No cases of induced persistent $\mathrm{CL}$ by uterine infection of catarrhal or mucopurulent types, were found, based on rectal palpation (i.e. finding CL in the same ovary and at the same position, in two exames at intervals of 10 to 12 days), progesterone levels in the serum at intervals of seven days, visual observation of estrus and return of estrus after prostaglandin $\mathrm{F}_{2}$ a injection. The nine cases of uterine infection of purulent type, which induced anestrus through persistent $\mathrm{CL}$, accounted for: $0.3 \%$ of the 3408 examined cows; $0.5 \%$ of 1774 non pregnant cows; $2.3 \%$ of the 384 uterine infection detected (catarrhal, mucopurulent and purulent types); and $25.0 \%$ of 36 cows showing uterine infections of purulent type. The results showed a low prevalence of persistent $\mathrm{CL}$ induced by change of the luteolityc mechanism due to uterine infection, which does not represent an important cause of infertility in the studied dairy herds.
\end{abstract}

Keywords: reproduction; metritis; persistent corpus luteum; ovary; dairy cattle.

\section{Introdução}

O rebanho bovino nacional apresenta baixa eficiência reprodutiva, com intervalo de partos estimado em torno de 19 meses (Ferreira et al., 1997), conseqüência de alimentação deficiente, responsável pela alta taxa de animais em anestro (Ferreira et al., 1992), de elevada perda de estros não identificados, devido ao manejo inadequado em fazendas que uti- lizam a inseminação artificial ou monta controlada, e de doenças dos órgãos genitais que provocam infertilidade ou esterilidade nos animais.

Entre as doenças que afetam a reprodução, as infecções uterinas ocupam lugar de destaque (Callahan, 1969 ; Ferreira, Sá, 1987) e acarretam prejuízos por atrasar a involução uterina e exigir maior número de serviços por concepção, alongando

\footnotetext{
* Embrapa Gado de Leite. R. Eugênio do Nascimento, 610 Juiz de Fora, MG. CEP 36038-330 - E-mail: ademirmf@cnpgl.embrapa.br

** Faculdade de Veterinária, Universidade de Alfenas, Rod. MG 179, Km 0, Alfenas, MG. CEP 37130-000.
} 
o período de serviço e o intervalo de partos (Roberts, 1971), além de maiores gastos com medicamentos e mão-de-obra para o tratamento.

As infecções uterinas instalam-se mais freqüentemente no período puerperal (Elliot et al., 1968 ; Bouters, Vandeplasshe, 1977), no momento do parto ou imediatamente após (Zebrascki et al., 1977), principalmente pela acentuada dilatação da cérvix, da vagina e da vulva ao parto, permitindo contaminação com impurezas da região perineal. Além disso, os debris e fluidos presentes no útero, logo após o parto, constituem um bom meio para o crescimento bacteriano (Callahan, 1969).

Em vacas com boa condição corporal ao parto, a presença de anormalidades uterinas no puerpério, como a infecção uterina, não impede o aparecimento do primeiro estro, mas o corpo lúteo resultante desse estro pode persistir em alguns casos de infecções uterinas purulentas ou piometrites (Lansiaux, 1984). A persistência de corpo lúteo também pode ocorrer devido à infecção que pode se instalar após a inseminação mal conduzida, na monta com touros infectados ou em vacas gestantes, nos. casos de morte embrionária ou fetal por espécies de Campylobacter ou Trichomonas, e na maceração ou mumificação fetal.

O corpo lúteo persistente perpetua a condição patológica, provavelmente por manter o útero sob a influência da progesterona, favorecendo a multiplicação de microrganismos ao reduzir a resistência do endométrio à infecção (Jackson, 1977). O corpo lúteo torna-se persistente em virtude de o útero infectado não ter habilidade para produzir prostaglandina $\mathrm{F}_{2} \mathrm{a}$, fator luteolítico natural (Lansiaux, 1984).

O objetivo do presente trabalho foi verificar a prevalência de corpo lúteo persistente associado às infecções uterinas em vacas leiteiras e avaliar sua importância como causa de infertilidade em rebanhos leiteiros da Zona da Mata de Minas Gerais.

\section{Material e métodos}

Realizou-se o exame ginecológico de 3.408 vacas, na quase totalidade mestiças Holandês $\times$ Zebu, de 50 rebanhos leiteiros localizados em 11 municípios da Zona da Mata de Minas Gerais. As condições do útero (tamanho, consistência, conteúdo) foram avaliadas em todos os animais por palpação transretal, massageando-se o órgão das vacas não gestantes no sentido crânio-caudal, na tentativa de aumentar o fluxo de material na cérvix e facilitar o diagnóstico pelo uso de vaginoscópio. Identificaram-se aquelas com fluxo contínuo e secreção anormal através da cérvix, caracterizando a infecção no útero.

A classificação das infecções uterinas baseou-se no aspecto do material que fluía da cérvix, conforme descrito por Dawson (1960): a) Primeiro grau (muco turvo ou catarral); b) Segundo grau (mucopurulento); c) Terceiro grau (purulento). O estádio reprodutivo dos animais que apresentavam secreção uterina anormal e presença de corpo lúteo $(C L)$ no primeiro exame foi reavaliado através de novo exame dos ovários 10-12 dias após, por palpação retal, para se verificar a permanência do corpo lúteo $(\mathrm{CL})$ no mesmo ovário e posição.

Caracterizou-se o CL persistente associado à infecção uterina quando da associação das seguintes condições: presença de CL no mesmo ovário e posição em dois exames consecutivos com intervalo de 10-12 dias, ausência de estro por observação visual, presença de exsudato purulento fluindo pelo canal cervical, ausência de prenhez, níveis de progesterona $\geq$ $1,5 \mathrm{mg} / \mathrm{mL}$ no primeiro exame e em coletas seguintes, e retorno ao estro após a aplicação de cloprostenol.

O estro foi identificado por observação visual duas vezes ao dia (manhã e tarde), e verificado o histórico de estros anteriores nas fazendas que efetuavam anotações.

Avaliou-se a condição corporal de cada vaca, obedecendo ao seguinte critério: a) Magra (ruim) - ossos protusos e pele aderida ao tecido inferior; b) Regular - sem depósitos visíveis de gordura, mas sem proeminência das partes angulares do "esqueleto"; c) Boa - depósitos de gordura visíveis em várias partes do corpo.

O sangue $(8 \mathrm{~mL})$ para análise de progesterona (RIA, kits comerciais) foi coletado em tubos de vidro vacuolizados, nas vacas com corpo lúteo e secreção anormal da cérvix no primeiro exame, e depois a cada sete dias (Lansiaux, 1984), no mínimo nove coletas (três períodos de estro/animal), por punção de veia ou artéria coccígea. Em seguida, foi centrifugado para obtenção do soro, que foi mantido em congelador a $-10^{\circ} \mathrm{C}$. Nas vacas consideradas com CL persistente foi aplicada uma injeção intramuscular de $500 \mathrm{mg}$ de cloprostenol, para provocar luteólise e aparecimento do estro, confirmando-se a presença de CL. Nesses animais, o sangue foi coletado no momento da aplicação de $\mathrm{PGF}_{2} \alpha$ e cinco dias após.

Nas fazendas estudadas foram observadas e anotadas algumas condições de exploração específicas, capazes de predispor ou determinar a instalação de infecções uterinas, tais como: tamanho do rebanho, idade das fêmeas, febre vitular, higiene e intervenções manuais ao parto, prevalência de prolapsos uterinos - partos distócicos - retenção de placenta, inseminação artificial mal conduzida, nível nutricional e de mineralização.

\section{Resultados e discussão}

O exame ginecológico de 3.408 fêmeas bovinas, em 50 rebanhos leiteiros da Zona da Mata de Minas Gerais - Brasil (média de 68 animais/rebanho), revelou 384 (11,3\%) infecções uterinas, das quais $186(5,5 \%)$ de primeiro grau ou catarral, $162(4,8 \%)$ do segundo grau ou mucopurulenta e $36(1,1 \%)$ do terceiro grau ou purulenta. A taxa de infecções uterinas purulentas ou de terceiro grau, inclusive aquelas associadas com corpo lúteo persistente, é mostrada na Tabela 1 . Os $11,3 \%$ de infecções uterinas encontradas no presente trabalho assemelham-se aos $10,8 \%$ verificados em levantamento efetuado por Canuto (1990) em rebanhos do litoral norte e Vale do Itajai, em Santa Catarina.

Tabela 1: Distribuição de 36 casos de infecção uterina purulenta entre vacas ciclando e em anestro, com ou sem corpo lúteo persistente

\begin{tabular}{lccccccc}
\hline \multirow{2}{*}{ Perío do pós-parto } & \multicolumn{2}{c}{ Anes tro } & \multicolumn{2}{c}{ Ciclando } & \multicolumn{2}{c}{ Total } \\
\cline { 2 - 7 } & $\mathrm{N}$ & $\%$ & $\mathrm{~N}$ & $\%$ & $\mathrm{~N}$ & $\%$ \\
\hline Até 90 dias pós-parto & 10 & 27,8 & 02 & 5,5 & 12 & 33,3 \\
Com CL persistente & 03 & 8,3 & - & - & - & - \\
Acima de 90 dias pós-parto & 14 & 38,9 & 10 & 27,8 & 24 & 66,7 \\
$\quad$ Com CL persistente & 06 & 16,7 & - & - & - & - \\
Total & $\mathbf{2 4}$ & 66,7 & $\mathbf{1 2}$ & $\mathbf{3 3 , 3}$ & $\mathbf{3 6}$ & $\mathbf{1 0 0 , 0}$ \\
\hline
\end{tabular}


Verifica-se na Tabela 1 que, das 36 vacas com infecção de terceiro grau (purulenta), 24 encontravam-se em anestro, das quais nove apresentavam corpo lúteo persistente. Dessas, em duas a condição corporal era boa e em quatro regular, enquanto três apresentavam-se magras, mostrando que a presença da patologia independe do estado corporal do animal. Como se sabe que a vaca magra quase sempre não apresenta estro e ovulação (Ferreira, 1990), é provável que o CL persistente presente tenha se originado de uma ovulação ocorrida quando o animal ainda apresentava condição corporal boa ou regular e persistiu devido ao acúmulo de exsudato purulento na cavidade uterina.

Os nove casos de anestro provocados por persistência de corpo lúteo, associado à infecção uterina, representaram 0,3\% do total de 3.408 vacas examinadas ou $2,3 \%$ do total de 384 casos diagnosticados de infecções uterinas. Esse índice representa também $0,5 \%$ do total de 1.774 vacas diagnosticadas não-gestantes, entre o total examinado, ou 0,8\% das 1.076 vacas não-gestantes que apresentavam condição de anestro. A prostaglandina $F_{2} \alpha$ de origem uterina é o maior agente luteolítico causador da regressão do $\mathrm{CL}$ em ruminantes (Hansel e Convey, 1983). A persistência do CL, que pode ser diagnosticada por endoscopia, concentração de progesterona no sangue ou leite e ultra-som, é acompanhada por supressão dos sinais do estro (Ronayne et al., 1990). Esta concentração de progesterona no plasma mantém-se dentro dos níveis normais da fase luteal de.um ciclo estral, como no presente trabalho, em que os níveis de progesterona no sangue das vacas com corpo lúteo persistente variaram de 4,7 a $6,2 \mathrm{ng} / \mathrm{mL}$. Em todos os nove casos diagnosticados de $\mathrm{CL}$ persistente, dos quais quatro eram de fetos macerados, verificou-se acúmulo de pus no interior do útero, capaz de modificar o endométrio e alterar o mecanismo luteolítico, impedindo a regressão do $C L$.

Quando o CL persistente regride pelo uso de medicamentos, o ciclo estral reinicia-se normalmente, dependendo da condição corporal do animal, e o estro com ovulação ocorre, geralmente, dentro de dois a três dias. Nesse estudo, as vacas com CL persistente receberam uma aplicação intramuscular de $500 \mathrm{mg}$ de cloprostenol e manifestaram o estro dentro de dois a quatro dias (Adams, 1994), confirmando a presença do $C L$ persistente e eliminando grande quantidade de material uterino purulento.

Vários fatores citados como determinantes ou predisponentes de infecções uterinas (Callahan, 1969 ; Franzos,1970 ; Robert,1971 ; Badinand, 1976 ; Lomba, 1978, Duncansson,

\section{Conclusões}

Os resultados revelam uma baixa taxa de corpo lúteo persistente provocado por alteração do mecanismo luteolítico devido à infecção uterina, e mostram que a patologia descrita não representa uma causa importante de infertilidade em reba-

\section{Referências bibliográficas}

ADAMS, G.P. Control of ovarian foticular wave dynamics in catle: implications for syncronization and superestimulation. Theriogenology, v. 41, n. 7, p. 19-24, 1996.
1980 ; Lansiaux, 1984 ; Wagner, 1991 ; Cordeiro et al., 1992 ; Barragry, 1996) foram também observados nas condições de manejo dos rebanhos leiteiros estudados, pois a quase totalidade dos mesmos estavam sendo submetidos a manejo inadequado (déficit energético e protéico, vacas magras, falta de suplementação mineral, controle sanitário ausente ou insuficiente, condições higiênicas precárias, falta de assistência técnica, inseminação artificial mal conduzida, alta incidência de retenção de placenta, parto distócico etc.). Por esse motivo, esperava-se uma prevalência de infecções uterinas purulentas ou do terceiro grau maior do que os $1,1 \%(n=36)$ de casos verificados nas 3.408 vacas examinadas. Entretanto, essa baixa taxa pode ser devida ao fato de que grande parte dos animais examinados $(82,6 \%)$ havia parido há alguns meses e já tinham manifestado um ou alguns estros, suficientes para promover a eliminação parcial de secreção purulenta uterina, e não permitir o acúmulo de exsudato no órgão, capaz de impedir o endométrio de produzir a prostaglandina $F_{2} \alpha$, conforme descrito por Coulson (1978).

Jackson (1977) e Coulson (1978) afirmam que, na maioria dos casos de piometrites e endometrites purulentas, pela cronicidade do processo, a infecção está associada à presença de um corpo lúteo persistente. Tal afirmação não foi confirmada no presente trabalho, visto que dos 36 animais apresentando as condições uterinas citadas pelos autores, apenas nove (25\%) tinham CL persistente, incluídos quatro casos de fetos macerados. Dos 27 animais restantes, 15 encontravam-se em anestro por ovários inativos, em razão da deficiência nutricional comprovada pela sua condição corporal inferior (magra), enquanto 12 apresentavam atividade ovariana luteal cíclica na época do exame.

A Tabela 2 mostra um resumo dos resultados associando infecção uterina de terceiro grau, corpo lúteo persistente e atividade ovariana.

Tabela 2: Infecções uterinas purulentas (terceiro grau) e corpo lúteo persistente em vacas mestiças Holandês $x$ Zebu

\begin{tabular}{lll}
\hline Infecções Uterinas do $3^{\circ}$ Grau & n & $\%$ \\
\hline Total de infecções uterinas do $3^{\circ}$ grau & 36 & 100 \\
Com corpo lúteo persistente & 9 & 25 \\
Sem corpo lúteo persistente & 27 & 75 \\
\hline
\end{tabular}

nhos leiteiros da Zona da Mata de Minas Gerais. Entretanto, as altas taxas de infecções uterinas de primeiro, segundo e terceiro graus demonstram que essas patologias uterinas ocupam lugar de destaque entre os fatores responsáveis pela baixa eficiência reprodutiva dos rebanhos leiteiros.

BADINAND, F. Métrites puerpérales enzootiques chez la vache; importance relative des differents facteurs d'apparition. Rec. Méd. Vét., v. 152, n. 2, p. 87-93, 1976.

BARRAGRY, T.O.M. Therapy of bovine metritis. Irish Vet. J., v. 49, n. 5 , p. 303-305, 1996. 
BOUTERS, R., VANDEPLASSHE, M. Post-partum infections in cattle; diagnosis and preventive and curative treatment. J. South Afr. Vet. Assoc., v. 48, n. 4, p. 237-239, 1977.

CALLAHAN, C.J. Post parturient infections of dairy cattle. J.A.V.M.A., v. 155, n. 12., p. 1963-1967, 1969.

CANUTO, L.A.T. Infecções uterinas em vacas leiteiras. Agrop. Catarinense, v. 3, n. 4, p. 9-10, 1990.

CORDEIRO, J.L.F., ALBUQUERQUE, A.J.D., NEVES, J.P., BADKE, M.R.T. Diagnóstico etiológico de catarros genitais em vacas leiteiras. $\mathrm{Ci}$ ência Rural, v. 22, n. 2, p. 213-218, 1992.

COULSON, A. Treatment of metritis in cattle with prostaglandin $F_{2}$ alpha. Vet. Rec., v. 103, n. 16, p. 359, 1978.

DAWSON, F.L.M. Bovine endometritis: a review. Br. Vet. J., v. 116, n. 12, p. 448-467, 1960.

DUNCANSSON, G.A. A four years study on a hundred and twenty cows dairy units. INTERNATIONAL CONGRESS ONDISEASESOF CATTLE, 11., 1980, Tel-Aviv. Proceedings..., 1980. p. 981-985.

ELLIOT, L.; MCMAHON, K.J.; GIER, H.T.; MARION, G.B. Uterus of the cow after parturition; bacterial content. Am. J. Vet. Res., v. 29, n. 1., p. 77-81, 1968.

FERREIRA, A.M., SÁ, W.F. Estudo das infecções uterinas em vacas leiteiras. PAB, v. 22, n. 3, p. 339-344, 1987.

FERREIRA, A.M. Efeito da amamentação e do nível nutricional na atividade ovariana de vacas mestiças leiteiras. $1990.132 \mathrm{p}$. Tese (Doutorado) - Universidade Federal de Viçosa.

FERREIRA, A.M., SÁ, W.F., VILLAÇA, H.A., ASSIS, A.G. Diagnóstico da situação produtiva e reprodutiva em rebanhos leiteiros da Zona da Mata - MG. PAB, v. 27, n. 7, p. 91-104, 1992.

FERREIRA, A.M, TEIXEIRA, S.R., SANTOS, P.C.B. dos, VERNEQUER, R.da S. Taxa de natalidade em rebanhos leiteiros do Estado do Rio de Janeiro. Rev. Bras. Reprod. Anim., V. 21, n. 2, p. 123-124, 1997.
FRANZOS, G. Observation on the relationship between overfeeding and the incidence of metritis in cows after normal parturition. Refuah Vet., v. 27, p. 148-155, 1970.

HANSEL, W., CONVEY, E.M. Physiology of the estrous cycle. J. Anim. Sci., v. 57, Suplem. 2, p. 404-424, 1983.

JACKSON, P.S. Treatment of chronic postpartum endometritis in cattle with cloprostenol. Vet. Rec., v. 101, n. 22, p. 441-443, 1977.

LANSIAUX, R.J.J. Les endometrites subaigues du postpartum chez la vache. Rôle de la prévention dans le contrôle de la fertilité du troupeau. 1984. 106 p. Tese (Doutorado) - Toulouse: École National de Vétérinaire.

LOMBA, F. Les endometrites en troupeaux laitiers à haute production. Bulletin GTV, v. 78, p.5B-137, 1978.

MAYER, E. Relations entre alimentation et infécondité. Bulletin GTV, v. 78 p. 4B-1321, 1978.

MORROW, D. Effect of peripartum diseases on postpartum reproduction in dairy cattle. J. Anim. Sci., v. 32, Suplem.1, p. 17-20, 1971.

ROBERTS, S.J. Veterinary obstetrics and genital disease. Ann. Arbor, Edwards Brothers, 1971.776 p.

RONAYNE, E., QUIRKE, J.F., ENRIGHT, W.J., ROCHE, J.F. Effect of immunization of ewes against prostaglandin $\mathrm{F}_{2} \mathrm{a}$ on the life-span of corpora lutea and oestrus behaviour during two breeding seasons. J. Reprod. Fert., v. 90, n. 1, p. 175-183, 1990.

WAGNER, W.C. Immunologic aspects of the uterus of the cow. CONGRESSO BRASILEIRO DE REPRODUÇÃO ANIMAL, 9., v. 1, 1991, Belo Horizonte. p. 93-107.

ZEBRASCKI, A., ZEZULA-SZPYRA, A., GLAZERT, T., LUBIENIECKI, B. Program of post-natal infection therapy in cows. INTERNATIONAL CONGRESS ON ANIMAL REPRODUCTION AND ARTIFICIAL INSEMINATION, 8., 1976, Krakow. Proceedings... , 1977. v. 6, p. 675-677. 